\title{
Correction to: The calculation of the solubility of metal hydroxides, oxide-hydroxides, and oxides, and their visualisation in logarithmic diagrams
}

\author{
Fritz Scholz $^{1}$ (D) $\cdot$ Heike Kahlert ${ }^{1}$
}

Published online: 27 December 2021

(c) Springer Nature Switzerland AG 2021

\section{Correction to: ChemTexts (2015) 1:7 https://doi.org/10.1007/s40828-015-0006-0}

We regret the misprint of the last two equations given in Table 2 in the original article.

The correct equations for a metal oxide of the specific stoichiometry $\mathrm{M}_{2} \mathrm{O}_{3}$ are as follows:

$\log S_{\mathrm{M}_{2} \mathrm{O}_{3}}=\log 0.5+0.5 \log K_{\mathrm{sol}, \mathrm{M}_{2} \mathrm{O}_{3}}+3 \mathrm{p} K_{\mathrm{w}}-3 \mathrm{pH}$

$\log S_{\mathrm{M}_{2} \mathrm{O}_{3}}=\log 0.5+0.5 \log K_{\mathrm{sol}, \mathrm{M}_{2} \mathrm{O}_{3}}+42.0-3 \mathrm{pH}$
The original article can be found online at https://doi.org/10.1007/ s40828-015-0006-0.

Fritz Scholz

fscholz@uni-greifswald.de

1 Institute of Biochemistry, University of Greifswald, Felix-Hausdorff-Str. 4, 17487 Greifswald, Germany
Publisher's Note Springer Nature remains neutral with regard to jurisdictional claims in published maps and institutional affiliations. 